\title{
Cefepime dosing regimens in critically ill patients receiving continuous renal replacement therapy: a Monte Carlo simulation study
}

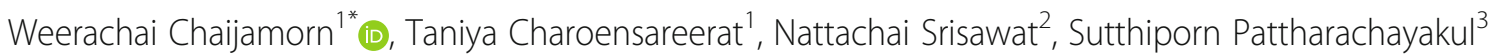
and Apinya Boonpeng ${ }^{4}$

\begin{abstract}
Background: Cefepime can be removed by continuous renal replacement therapy (CRRT) due to its pharmacokinetics. The purpose of this study is to define the optimal cefepime dosing regimens for critically ill patients receiving CRRT using Monte Carlo simulations (MCS).

Methods: The CRRT models of cefepime disposition during $48 \mathrm{~h}$ with different effluent rates were developed using published pharmacokinetic parameters, patient demographic data, and CRRT settings. Pharmacodynamic target was the cumulative percentage of a 48-h period of at least $70 \%$ that free cefepime concentration exceeds the four times susceptible breakpoint of Pseudomonas aeruginosa (minimum inhibitory concentration, MIC of 8). All recommended dosing regimens from available clinical resources were evaluated for the probability of target attainment (PTA) using MCS to generate drug disposition in a group of 5000 virtual patients for each dose. The optimal doses were defined as achieving the PTA at least $90 \%$ of virtual patients with lowest daily doses and the acceptable risk of neurotoxicity.

Results: Optimal cefepime doses in critically ill patients receiving CRRT with Kidney Disease: Improving Global Outcomes (KDIGO) recommended effluent rates were a regimen of $2 \mathrm{~g}$ loading dose followed by $1.5-1.75 \mathrm{~g}$ every $8 \mathrm{~h}$ for Gramnegative infections with a neurotoxicity risk of $<17 \%$. Cefepime dosing regimens from this study were considerably higher than the recommended doses from clinical resources.
\end{abstract}

Conclusion: All recommended dosing regimens for patients receiving CRRT from available clinical resources failed to achieve the PTA target. The optimal dosing regimens were suggested based on CRRT modalities, MIC values, and different effluent rates. Clinical validation is warranted.

Keywords: Cefepime, Dosing, Pharmacokinetics, Pharmacodynamics, Continuous renal replacement therapy, Critically ill patients

\section{Background}

Continuous renal replacement therapy (CRRT) is generally performed in hemodynamic unstable patients with acute kidney injury (AKI) [1]. Cefepime is an antimicrobial agent that is commonly used in critically ill patients. The low protein binding affinity (16-20\%) and small

\footnotetext{
* Correspondence: weerachai.cha@siam.edu

${ }^{1}$ Faculty of Pharmacy, Siam University, 38 Petkasem Road, Bangwa,

Pasicharoen, Bangkok 10160, Thailand

Full list of author information is available at the end of the article
}

volume of distribution (14-20 L) make cefepime susceptible to be removed by CRRT [2-4].

Pharmacokinetic changes in critically ill patients, such as increasing of volume of distribution and hypoalbuminemia, considerably reduce hydrophilic antimicrobial agent concentrations [5]. Consequently, we might have prescribed inadequate doses of antimicrobial agents in patients with CRRT [5] and unintentionally increase the morbidity and mortality associated with sepsis [6]. The primary aim of drug dosing in this population is to use the loading dose (LD) and adequate maintenance doses

(c) The Author(s). 2018 Open Access This article is distributed under the terms of the Creative Commons Attribution 4.0 International License (http://creativecommons.org/licenses/by/4.0/), which permits unrestricted use, distribution, and 
to attain pharmacokinetic and pharmacodynamic targets for maximizing antibacterial killing effect and therapeutic outcome [7].

Cefepime dosing recommendations in critically ill patients are based on previously published pharmacokinetic studies [2, 5, 8, 9]. Interestingly, Li and colleagues gathered and analyzed 64 published pharmacokinetic studies in patients receiving CRRT. They revealed that those studies did not completely report key pharmacokinetic parameters to calculate extracorporeal clearance and design drug dosing in patient with CRRT such as type of CRRT modalities, effluent rate, blood flow rate, and extraction coefficient [10]. Some studies used old CRRT techniques or hemofilters and low effluent rates [10]. Neurotoxicity from high cefepime concentrations in patients with reduced renal function has been reported [11-15].

Our study aimed to use the Monte Carlo simulation (MCS) technique to define the proper dosing of cefepime in AKI patients who require CRRT support.

\section{Methods}

\section{Mathematical pharmacokinetic models}

A literature search was performed using the following medical subject heading (MeSH) terms: (1) 'cefepime', (2) 'continuous renal replacement therapy' or 'continuous venovenous hemofiltration' or 'continuous venovenous hemodialysis', and (3) 'pharmacokinetics' and synonymous words in PubMed. EMBASE and EBSCO were searched with slightly different search terms due to differences of each database. All publications that entered the databases by 31 December 1990 were included. Two investigators (WC and TC) independently identified and evaluated studies for potential inclusion. We restricted our search to articles conducted in adult human subjects and critically ill subjects receiving CRRT. All publications focused on drug pharmacokinetics were gathered. We included only publications that reported all necessary pharmacokinetic parameters for calculation of cefepime dosing regimens. Any disagreement on inclusion was resolved by discussion between the two reviewers. We identified 50 publications, of which 6 were considered relevant and were evaluated [8, 9, 16-19]. All previously published pharmacokinetic studies of cefepime reported only basic pharmacokinetic parameters such as volume of distribution, total drug clearance, non-renal clearance, extraction coefficient, and elimination rate constant $[8,9,16-19]$. In addition, Carlier and colleagues revealed that a one-compartment pharmacokinetic model best fits to describe cefepime characteristics [19]. Consequently, a one-compartment mathematical pharmacokinetic model with first-order elimination of acute kidney disease patients receiving CRRT was developed to predict cefepime disposition in $48 \mathrm{~h}$ of the initial therapy. Assuming the patients were anuric, renal clearance applied in the model was $0 \mathrm{~mL} / \mathrm{min}$. Previously published cefepime pharmacokinetic parameters in critically ill patients $[8,9,16-19]$ and related variability from critically ill patients receiving CRRT were gathered to create models of virtual patients with three modalities. Two thirds of patients in previously published studies were diagnosed as sepsis and septic shock and needed CRRT treatment. Different CRRT settings affect drug dosing [20], and no specific technique of CRRT modality for AKI management is recommended [1]. The commonly used modalities consisted of continuous venovenous hemofiltration $(\mathrm{CVVH})$ with pre-hemofilter dilution techniques, in which replacement fluid is added in blood before going through hemofilter and continuous venovenous hemodialysis (CVVHD) [20]. To construct realistic virtual patients, we added populationspecific correlation $\left(r^{2}\right)$ between patient's body weight, non-renal clearance, and volume of distribution into the models. The lower limit of body weight was set at $40 \mathrm{~kg}$ assuming that the virtual patients are adult. In addition, body weights used in the models of virtual patients were obtained from an international database of the International Society of Nephrology (ISN)-funded prospective multicenter observational ongoing study of AKI epidemiology in Southeast Asia entitled The Epidemiology and Prognostic Factors for Mortality in Intensive Care Unit Patients with Acute Kidney Injury in Southeast Asia (SEA-AKI) [21]. It enrolled 6644 critically ill patients from Thailand, Laos, and the Philippines. All described pharmacokinetic parameters are defined in Table 1.

Transmembrane drug clearance was calculated as multiplying effluent flow rate, dialysate $\left(Q_{\mathrm{d}}\right)$ and/or ultrafiltrate $\left(Q_{\mathrm{uf}}\right)$ flow rate, by extraction coefficient that are sieving coefficient (SC) for hemofiltration and saturation coefficient (SA) for hemodialysis [20]. Total drug clearance was calculated from the summation of non-renal clearance and CRRT clearance. To calculate drug concentration profile in $48 \mathrm{~h}$ of initial therapy for evaluation of the probability of target attainment (PTA), elimination rate constant $(k)$ was determined by total

Table 1 Parameters used in these models of virtual AKI patients receiving CRRT [14-18]

Pharmacokinetic parameters

Mean \pm SD (range limits)

\begin{tabular}{lll}
\hline & Hemofiltration (HF) & Hemodialysis (HD) \\
\hline Weight $(\mathrm{kg})$ & $60.72 \pm 14.5(40-230)$ & \\
$V_{\mathrm{d}}(\mathrm{L} / \mathrm{kg})$ & $0.5 \pm 0.23(0.21-1.11)$ & \\
$\mathrm{CL}_{\mathrm{NR}}(\mathrm{mL} / \mathrm{min})$ & $24.33 \pm 11.25(13-44)$ & \\
Free fraction & $0.79 \pm 0.09(0.72-0.85)$ & \\
SC or SA & $0.79 \pm 0.15(0.47-0.92)$ & $0.77 \pm 0.09(0.65-0.97)$ \\
\hline
\end{tabular}


drug clearance divided by volume of distribution. The $k$ value was required to calculate drug concentration at a time. Blood flow rate $\left(Q_{\text {blood }}\right)$ for all settings was prescribed as $200 \mathrm{~mL} / \mathrm{min}$. The equations used in the models were defined as follows [20]:

$$
\begin{aligned}
& \mathrm{CL}_{\mathrm{HD}}(L / h)=\mathrm{SA} \times \mathrm{Q}_{\mathrm{d}} \\
& \mathrm{C} \mathrm{L}_{\mathrm{HF}(\text { pre })} \quad(L / h)=\mathrm{SC} \times Q_{\mathrm{uf}} \times\left[Q_{\text {plasma }} /\left(Q_{\text {plasma }}+\right.\right. \\
& \left.\left.Q_{\text {replacement }}\right)\right] \\
& k=\left(\mathrm{CL}_{\mathrm{NR}}+\mathrm{CL}_{\mathrm{HD}}\right) / V_{\mathrm{d}} \\
& k=\left(\mathrm{CL}_{\mathrm{NR}}+\mathrm{CL}_{\mathrm{HF}}\right) / V_{\mathrm{d}}
\end{aligned}
$$

where $C L_{H F}$ is the transmembrane clearance in hemofiltration, $Q_{\text {plasma }}$ is the plasma flow rate $\left(Q_{\text {plasma }}=Q_{\text {blood }} \times\right.$ (1-hematocrit)), hematocrit is $30 \%, Q_{\text {replacement }}$ is the replacement fluid flow rate $\left(Q_{\text {replacement }}=Q_{u f}\right), C L_{H D}$ is the transmembrane clearance in hemodialysis, $Q_{\mathrm{d}}$ is the dialysate flow rate, $k$ is the elimination rate constant, $\mathrm{CL}_{\mathrm{NR}}$ is the non-renal clearance, and $V_{\mathrm{d}}$ is the volume of distribution.

Effluent rates were prescribed as Kidney Disease: Improving Global Outcomes (KDIGO) recommendation of $20-25 \mathrm{~mL} / \mathrm{kg} / \mathrm{h}$ [1]. A higher effluent rate of $35 \mathrm{~mL} / \mathrm{kg} /$ $\mathrm{h}$ was included in the models to reflect an average common effluent rate used in real-life practice or when high-volume CRRT is needed [22]. Moreover, lower effluent rates of $10-15 \mathrm{~mL} / \mathrm{kg} / \mathrm{h}$ were performed to aid cefepime dosing when low-volume CRRT was prescribed in some situations.

\section{Cefepime dosing recommendations}

Cefepime dosing regimens from available drug dosing recommendations were evaluated in the models. The dosing regimens varied from 1 to $2 \mathrm{~g}$ every $12 \mathrm{~h}$ to $2 \mathrm{~g}$ loading dose followed by $1 \mathrm{~g}$ every $8 \mathrm{~h}$ or $2 \mathrm{~g}$ every $12 \mathrm{~h}$ [23-25].

\section{Monte Carlo simulation and probability of target attainment}

Following a previously published method [26, 27], Monte Carlo simulation (Crystal Ball Classroom edition, Oracle) generates drug concentration-time profiles of a group of 5000 virtual patients for each dose to evaluate the PTA. PTA was predicted using pharmacodynamic target of the cumulative percentage of a 48-h period that free cefepime concentration exceeds the minimum inhibitory concentration (MIC) of Pseudomonas aeruginosa [28]. Given that microbiological success (eradication or presumed eradication) was significantly associated with the proportion of the dosing interval in which cefepime concentration exceeded four times MIC [29] and the cumulative percentage of free cefepime concentration needed to exceed the MIC, 70\% coverage is required to achieve the maximal bactericidal effect $[17,18,30]$. In this study, at least $70 \%$ of the cumulative percentage of a 48 -h period with four times MIC $\left(70 \% \mathrm{fT}_{>4 \mathrm{MIC}}\right)$ and susceptible breakpoint recommended by the Clinical Laboratory Standards Institute
(CLSI) [31] for P. aeruginosa (8 $\mathrm{mg} / \mathrm{L})$ were applied in the models for the first $48 \mathrm{~h}$ of initial cefepime therapy. Owing to the differences of the MIC in various health care settings, we also used the MICs of 1,2 , and $4 \mathrm{mg} / \mathrm{L}$ in the models to define the optimal dosing regimens for each MIC in the study. The optimal doses were defined as achieving the PTA target of at least $90 \%$ of 5000 virtual patients with the lowest daily dose to emphasize cefepime efficacy and consider the risk of toxicity especially neurotoxicity as described below. Different cefepime dosing regimens including recommendations for critically ill patients were evaluated to define the optimal doses.

\section{Cefepime neurotoxicity}

Neurotoxicity of cefepime, defined as confusion, hallucination, convulsion, seizure, and encephalopathy, has been noted in various studies. Most studies in patients with reduced renal function reported cefepime trough concentrations associated with neurotoxicity as an average of 76 (9-224) $\mathrm{mg} / \mathrm{L}$ [11-15]. We used the concentration of $70 \mathrm{mg} / \mathrm{L}$ to be a threshold for expected neurotoxicity that could occur from cefepime in AKI patients receiving CRRT. All cefepime dosing regimens were evaluated for the possibility to develop neurotoxicity at 48-h trough concentration. The optimal doses were required to achieve a previously described target and had the lowest risk of occurring $\geq 70 \mathrm{mg} / \mathrm{L}$ of cefepime concentrations in drug concentration-time profiles of 5000 virtual patients for each regimen.

\section{Results}

Characteristics of selected virtual patients who achieve the pharmacodynamic target with the optimal dosing regimens as described in the "Methods" section were compared with input parameters from previously published studies and are shown in Table 2.

Table 3 summarizes the PTA results of selected cefepime dosing regimens for treating $P$. aeruginosa using MICs of 1, 2, 4, and 8 on the first $48 \mathrm{~h}$ of therapy. The probability of developing neurotoxicity of each regimen of two CRRT modalities and five different effluent rates was presented in Table 4. Applying the aggressive target as CLSI recommended MIC breakpoint of $8 \mathrm{mg} / \mathrm{L}$ into the models, all recommended dosing regimens from clinical resources could not attain the targets with two different modalities. Considering efficacy from the PTA target and the probability of developing neurotoxicity, the regimen of $2 \mathrm{~g}$ loading dose followed by $1.5-1.75 \mathrm{~g}$ every $8 \mathrm{~h}$ achieved the aforementioned targets of $>90 \%$ for all CRRT settings with KDIGO recommended effluent rates in a range of $20-25 \mathrm{~mL} / \mathrm{kg} / \mathrm{h}$ (Table 5). In addition, the probability of neurotoxicity occurred when cefepime concentrations $>70 \mathrm{mg} / \mathrm{L}$ at $48 \mathrm{~h}$ was approximately $0.06-17 \%$ (Table 4). The PTA of cefepime 
Table 2 Virtual patient characteristics compared with input pharmacokinetic parameters from published cefepime studies

\begin{tabular}{lll}
\hline $\begin{array}{l}\text { Pharmacokinetic } \\
\text { parameters }\end{array}$ & $\begin{array}{l}\text { Literature-based values } \\
(\text { mean } \pm S D(\text { range limits })) \\
(N=37)\end{array}$ & $\begin{array}{l}\text { Simulation-based values } \\
(\text { mean } \pm S D(r a n g e ~ l i m i t s)) \\
(N=5000)\end{array}$ \\
\hline Weight $(\mathrm{kg})$ & $60.72 \pm 14.5(40-230)$ & $61.88 \pm 13.77(40.01-142.22)$ \\
$V_{\mathrm{d}}(\mathrm{L} / \mathrm{kg})$ & $0.5 \pm 0.23(0.21-1.11)$ & $0.49 \pm 0.19(0.21-1.11)$ \\
$\mathrm{CL}_{\mathrm{NR}}(\mathrm{mL} / \mathrm{min})$ & $24.33 \pm 11.25(13-44)$ & $24.21 \pm 7.63(13.00-43.99)$ \\
Free fraction & $0.79 \pm 0.09(0.72-0.85)$ & $0.78 \pm 0.04(0.72-0.85)$ \\
SC & $0.79 \pm 0.15(0.47-0.92)$ & $0.74 \pm 0.10(0.47-0.92)$ \\
SA & $0.77 \pm 0.09(0.65-0.97)$ & $0.78 \pm 0.07(0.65-0.97)$ \\
\hline
\end{tabular}

regimens according to various MICs, effluent rates, and CRRT modalities is presented in Table 3. The recommendations of cefepime regimens for critically ill patients receiving three different CRRT modalities, effluent rates, and various MICs are shown in Table 5.

If greater effluent rates such as $35 \mathrm{~mL} / \mathrm{kg} / \mathrm{h}$ are required, the cefepime dosing regimen for $P$. aeruginosa infection (MIC of $8 \mathrm{mg} / \mathrm{L}$ ) using the aggressive pharmacodynamic target was 2 g LD followed by 1.75-2 g every $8 \mathrm{~h}$ with a higher risk of cefepime-induced neurotoxicity $(\leq 33 \%)$ (Tables 4 and 5 ). When CRRT with lower effluent rates of $10-15 \mathrm{~mL} / \mathrm{kg} / \mathrm{h}$ was prescribed, the cefepime dosing regimen of $1.75 \mathrm{~g}$ loading dose followed by $1.5 \mathrm{~g}$ every $8 \mathrm{~h}$ was needed to achieve the aggressive target for $P$. aeruginosa infection (MIC of $8 \mathrm{mg} / \mathrm{L}$ ) (Table 4). Figure 1 illustrates the PTA at $70 \% \mathrm{fT}_{>4 \mathrm{MIC}}$ (MIC of $8 \mathrm{mg}$ / L) for selected cefepime dosing regimens of CVVHD with an effluent rate of $25 \mathrm{~mL} / \mathrm{kg} / \mathrm{h}$.

\section{Discussion}

This is the first simulation study applying MCS technique to evaluate cefepime dosing regimens for management of $P$. aeruginosa infection in critically ill patients. Pharmacokinetic parameters collected from previously published studies $[8,9,16-19]$, body weights as described in the "Methods" section, and CRRT settings with five different effluent rates $(10,15,20,25$, and $35 \mathrm{~mL} / \mathrm{kg} / \mathrm{h}$ ) [1, 22] were incorporated into the models to predict cefepime disposition in critically ill patients receiving CRRT for $48 \mathrm{~h}$. Moreover, correlations between used pharmacokinetic parameters were applied in the models to create population-specific virtual patients. As shown in Table 2, this study showed that MCS technique created virtual patient pharmacokinetics that were similar to which parameters gathered from previous studies. This technique therefore could be an effective tool to build realistic patients and guide drug dosing regimens in various groups of patients, especially this population.

The pharmacodynamic target of $70 \% \mathrm{fT}_{>4 \mathrm{MIC}}$ was associated with maximum bactericidal effects [17, 18, 30]. Given the results from Tam and colleagues, bactericidal activity of cefepime is optimized at concentrations approximately four times MIC [29]. We decided to apply aggressive target as $70 \% \mathrm{fT}_{>4 \mathrm{MIC}}$ in the models as aforementioned in the "Methods" section. However, using the aggressive target could lead to excessive drug dosages with the risk of cefepime-induced neurotoxicity. Clinical monitoring of cefepime adverse reactions should be concerned.

This study revealed that the regimen of $2 \mathrm{~g}$ loading dose followed by 1.5-1.75 g every $8 \mathrm{~h}$ achieved the PTA target for $P$. aeruginosa (MIC of $8 \mathrm{mg} / \mathrm{L}$ ) with two different modalities in $\geq 90 \%$ of virtual patients receiving CRRT with KDIGO recommended effluent rate of 20$25 \mathrm{~mL} / \mathrm{kg} / \mathrm{h}$. The expected neurotoxicity risk occurred with the suggested regimen from our simulations were in a range of $0.06-17 \%$ according to the effluent rates and CRRT modalities (Table 4). Clinical monitoring of cefepime-induced neurotoxicity is needed when the recommended cefepime dosing regimen is prescribed. Notably, no clinical recommended regimens exceeded the PTA target of $P$. aeruginosa. It was aligned with the results from Seyler et al. that they used the pharmacodynamic target of $70 \% \mathrm{fT}_{>4 \mathrm{MIC}}(8 \mathrm{mg} / \mathrm{L})$ which was $32 \mathrm{mg} /$ $\mathrm{L}$ as we applied in this study for $P$. aeruginosa. They revealed that the recommended doses of cefepime could not achieve the target for critically ill patients with CRRT for the first $48 \mathrm{~h}$ (0\% PTA) [18]. Moreover, dosing regimens for $P$. aeruginosa infection were different depending on MICs used in the simulations (Table 5). It explained that cefepime dosing regimens were associated with local MIC values in each setting.

The pharmacokinetic changes of hydrophilic drugs in critically ill patients such as increased volume of distribution due to fluid accumulation, decreased protein binding and metabolism can cause lower drug concentrations especially when conventional dosing regimens were used [5]. The cefepime volume of distribution gathered from critically ill patients and used in this study was approximately $30 \mathrm{~L}(0.5 \pm 0.23 \mathrm{~L} / \mathrm{kg})$. The value was larger than that reported in normal population (4-20 L) [2-4]. As volume of distribution is taken into account in a mathematical equation of drug clearance as $\mathrm{CL}=k \times V_{\mathrm{d}}$, it affects drug clearance and the probability of target attainment 


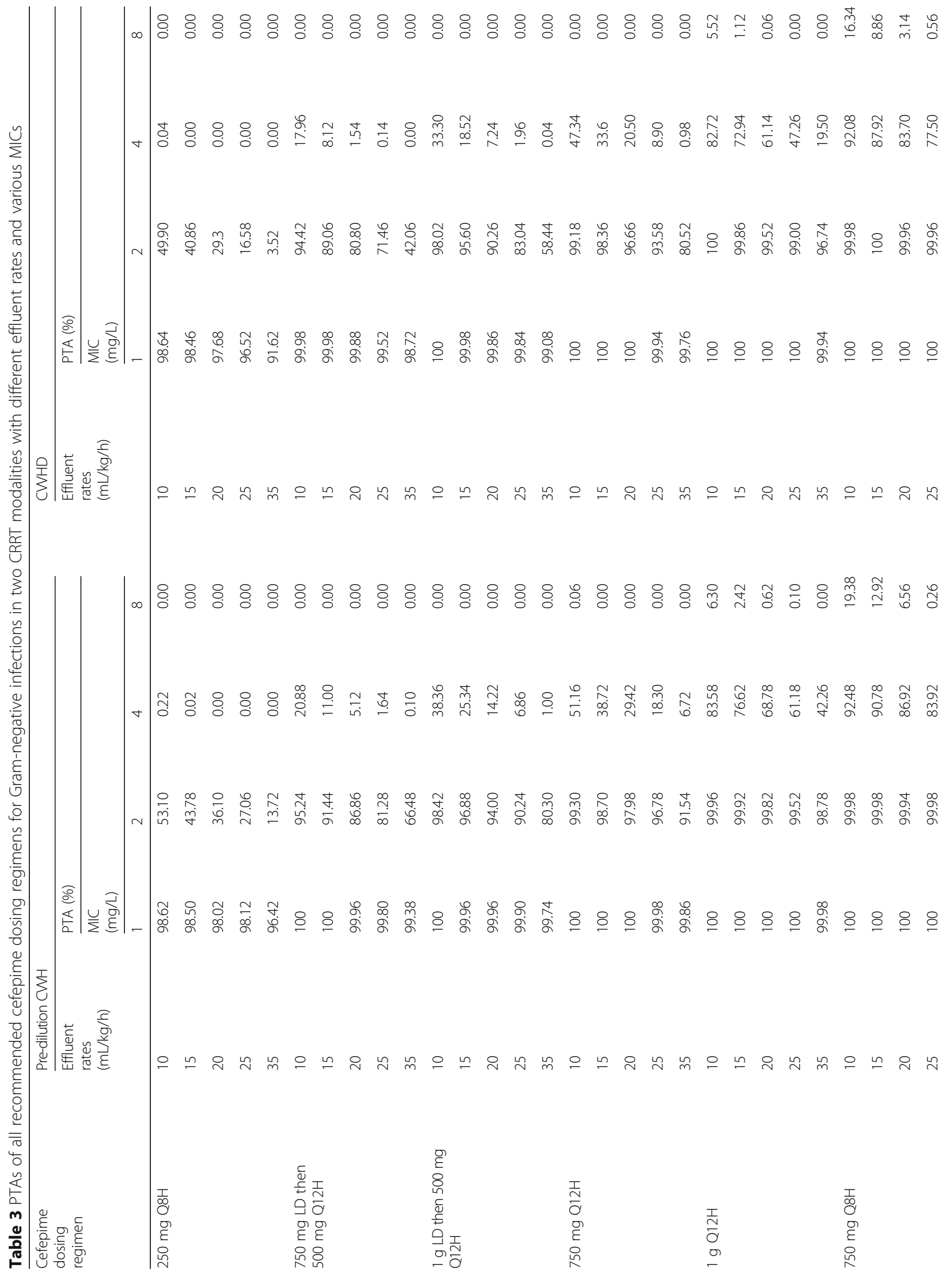




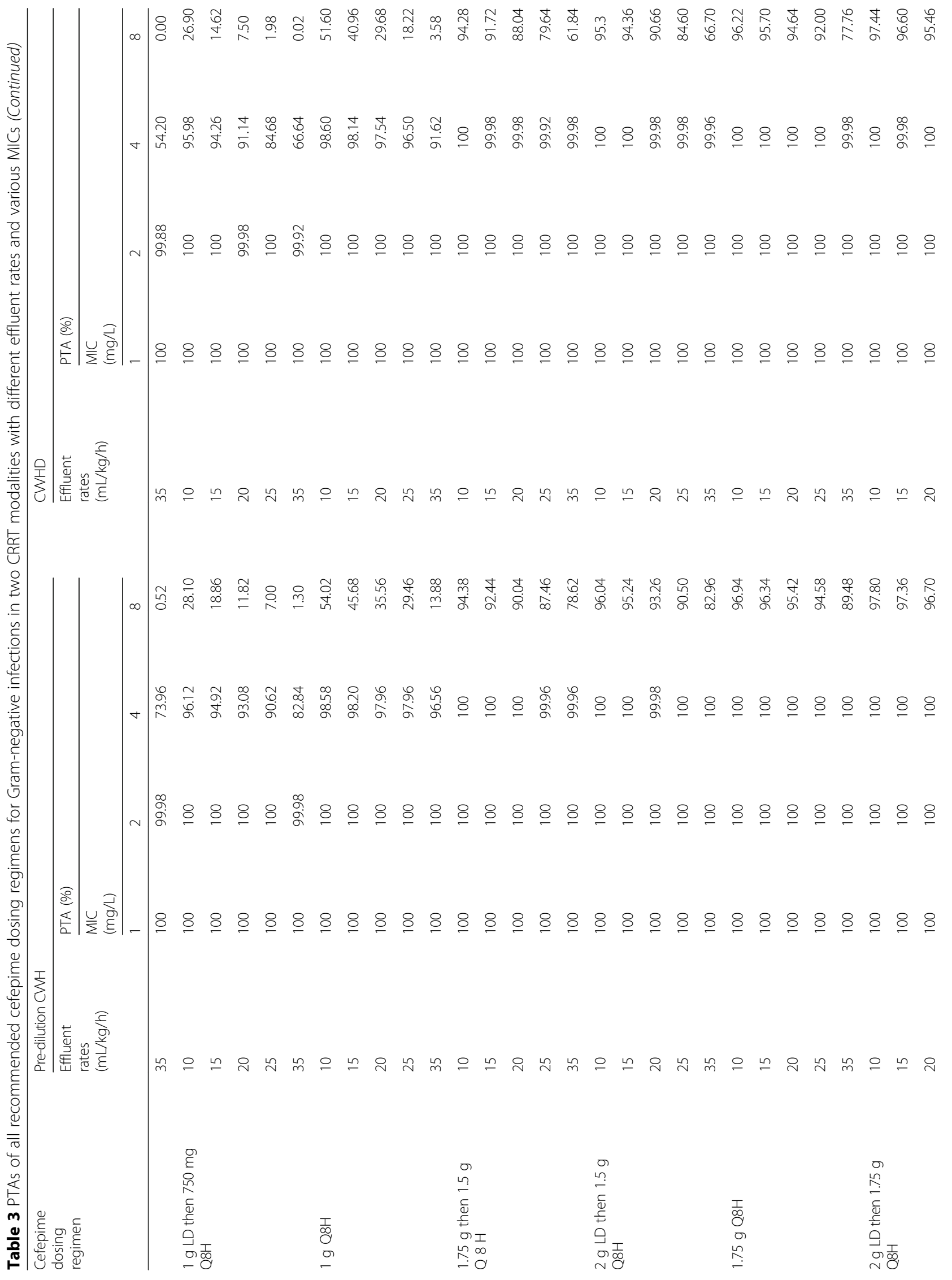


Chaijamorn et al. Journal of Intensive Care (2018) 6:61

Page 7 of 11

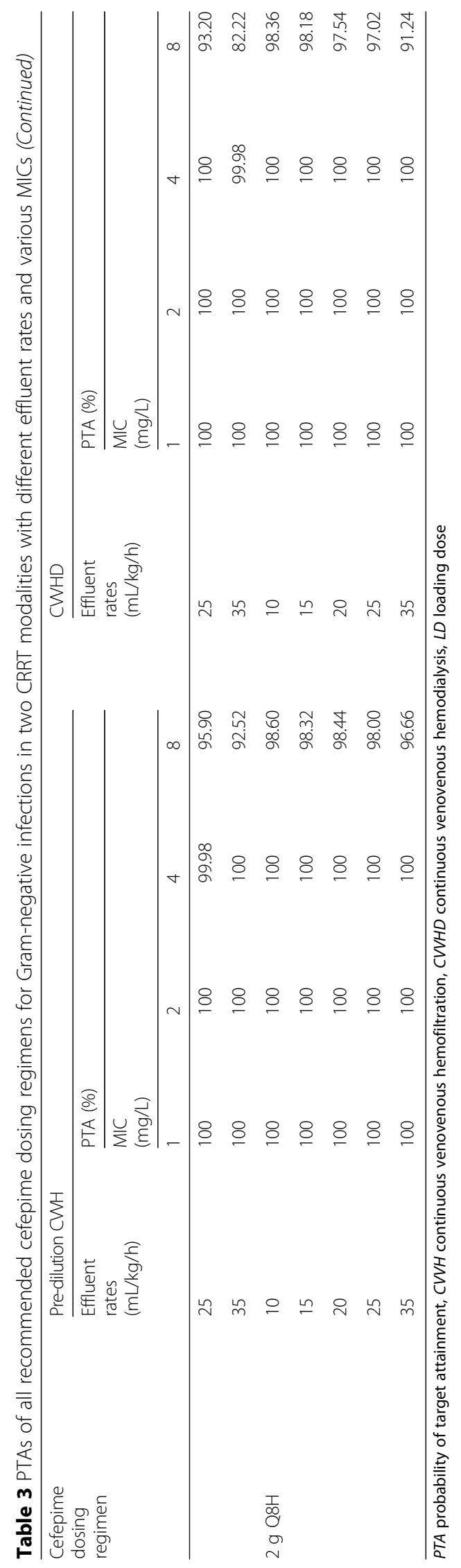


Table 4 The probability of developing neurotoxicity from selected cefepime dosing regimens

\begin{tabular}{|c|c|c|c|c|}
\hline \multirow{2}{*}{$\begin{array}{l}\text { Cefepime dosing } \\
\text { regimens }\end{array}$} & \multicolumn{2}{|c|}{ Pre-dilution $\mathrm{CWH}$} & \multicolumn{2}{|l|}{ CWHD } \\
\hline & $\begin{array}{l}\text { Effluent rate } \\
(\mathrm{mL} / \mathrm{kg} / \mathrm{h})\end{array}$ & $\begin{array}{l}\text { 48-h trough probability } \\
\geq 70 \mathrm{mg} / \mathrm{L}(\%)\end{array}$ & $\begin{array}{l}\text { Effluent rate } \\
(\mathrm{mL} / \mathrm{kg} / \mathrm{h})\end{array}$ & $\begin{array}{l}\text { 48-h trough probability } \\
\geq 70 \mathrm{mg} / \mathrm{L}(\%)\end{array}$ \\
\hline \multirow[t]{5}{*}{$1 \mathrm{~g} \mathrm{Q8H}$} & 10 & 0.18 & 10 & 0.04 \\
\hline & 15 & 0.00 & 15 & 0.00 \\
\hline & 20 & 0.00 & 20 & 0.00 \\
\hline & 25 & 0.00 & 25 & 0.00 \\
\hline & 35 & 0.00 & 35 & 0.00 \\
\hline \multirow[t]{5}{*}{$1.75 \mathrm{~g}$ LD then $1.5 \mathrm{~g} \mathrm{Q8H}$} & 10 & 26.28 & 10 & 22.30 \\
\hline & 15 & 11.54 & 15 & 7.02 \\
\hline & 20 & 4.46 & 20 & 1.44 \\
\hline & 25 & 1.26 & 25 & 0.08 \\
\hline & 35 & 0.14 & 35 & 0.00 \\
\hline \multirow[t]{5}{*}{$2 \mathrm{~g} \mathrm{LD}$ then $1.5 \mathrm{~g} \mathrm{Q8H}$} & 10 & 26.04 & 10 & 21.7 \\
\hline & 15 & 13.36 & 15 & 7.40 \\
\hline & 20 & 5.12 & 20 & 0.98 \\
\hline & 25 & 1.50 & 25 & 0.06 \\
\hline & 35 & 0.08 & 35 & 0.00 \\
\hline \multirow[t]{5}{*}{$1.75 \mathrm{~g} \mathrm{Q8H}$} & 10 & 45.44 & 10 & 41.30 \\
\hline & 15 & 29.14 & 15 & 22.24 \\
\hline & 20 & 16.84 & 20 & 7.82 \\
\hline & 25 & 7.96 & 25 & 1.94 \\
\hline & 35 & 1.22 & 35 & 0.04 \\
\hline \multirow[t]{5}{*}{$2 \mathrm{~g} \mathrm{LD}$ then $1.75 \mathrm{~g} \mathrm{Q8H}$} & 10 & 45.12 & 10 & 42.10 \\
\hline & 15 & 32.46 & 15 & 22.30 \\
\hline & 20 & 17.16 & 20 & 7.78 \\
\hline & 25 & 8.04 & 25 & 1.76 \\
\hline & 35 & 1.38 & 35 & 0.04 \\
\hline \multirow[t]{5}{*}{$2 \mathrm{~g} \mathrm{Q8H}$} & 10 & 61.04 & 10 & 58.10 \\
\hline & 15 & 47.86 & 15 & 40.52 \\
\hline & 20 & 33.48 & 20 & 20.84 \\
\hline & 25 & 20.90 & 25 & 8.98 \\
\hline & 35 & 6.52 & 35 & 0.26 \\
\hline
\end{tabular}

CVVH continuous venovenous hemofiltration, CVVHD continuous venovenous hemodialysis, $L D$ loading dose

when volume of distribution increases. Given that AKI patients may have well-preserved non-renal drug clearance [32], an average non-renal clearance gathered from previously published studies $(24.33 \pm 11.25 \mathrm{~mL} / \mathrm{min})$ was similar to the values reported from healthy volunteers and patients with renal insufficiency in a range of $10-30 \mathrm{~mL} /$ min $[3,4,33]$. Additionally, hypoalbuminemia occurred in ICU patients was reported in a range of $40-50 \%$ [34] and could increase free drug concentrations that would be removed by CRRT, the liver, and the kidney. Given these reasons described earlier, the loading dose concept is very crucial to attain the PTA target in these situations.
An effluent rate contributes to extracorporeal clearance defined by the described equation. Higher effluent rate requires a higher dose to compete the PTA target in the population. When CRRT setting was prescribed with an effluent rate of $35 \mathrm{~mL} / \mathrm{kg} / \mathrm{h}$, cefepime doses would be $2 \mathrm{~g}$ LD followed by $1.75-2$ g every $8 \mathrm{~h}$ for $P$. aeruginosa (MIC of $8 \mathrm{mg} / \mathrm{L}$ ) to achieve the PTA target. Undoubtedly, if the lower effluent rates of $10-15 \mathrm{~mL} / \mathrm{kg} / \mathrm{h}$ were utilized, the lower cefepime loading dose of $1.75 \mathrm{~g}$ was suggested with same maintenance doses as compared with using KDIGO-recommended effluent rates of $20-25 \mathrm{~mL} / \mathrm{kg} / \mathrm{h}$ (Table 5). 
Table 5 Recommendations of cefepime dosing regimens for treating P. aeruginosa infections with various MICs in critically ill patients receiving CRRT

\begin{tabular}{|c|c|c|c|c|}
\hline $\begin{array}{l}\text { Actual MIC } \\
\text { (mg/L) }\end{array}$ & $\begin{array}{l}\text { Target } \\
\text { MIC }^{*} \\
(\mathrm{mg} / \mathrm{L})\end{array}$ & $\begin{array}{l}\text { Effluent rates } \\
(\mathrm{mL} / \mathrm{kg} / \mathrm{h})\end{array}$ & $\begin{array}{l}\text { CWH } \\
\text { (pre-hemofilter dilution) }\end{array}$ & CWHD \\
\hline \multirow[t]{3}{*}{1} & 4 & $10-15$ & $250 \mathrm{mg} \mathrm{Q8H}$ & 250 mg Q8H \\
\hline & & $20-25$ & $250 \mathrm{mg} \mathrm{Q8H}$ & 250 mg Q8H \\
\hline & & 35 & $250 \mathrm{mg} \mathrm{Q8H}$ & 250 mg Q8H \\
\hline \multirow[t]{3}{*}{2} & 8 & $10-15$ & $\begin{array}{l}750 \mathrm{mg} \text { LD then } \\
500 \mathrm{mg} \mathrm{Q12H}\end{array}$ & $\begin{array}{l}1 \mathrm{~g} \mathrm{LD} \text { then } \\
500 \mathrm{mg} \mathrm{Q} 12 \mathrm{H}\end{array}$ \\
\hline & & $20-25$ & $\begin{array}{l}1 \mathrm{~g} \mathrm{LD} \text { then } \\
500 \mathrm{mg} \mathrm{Q} 12 \mathrm{H}\end{array}$ & $750 \mathrm{mg}$ Q12H \\
\hline & & 35 & 750 mg Q12H & $1 \mathrm{~g} \mathrm{Q12H}$ \\
\hline \multirow[t]{3}{*}{4} & 16 & $10-15$ & 750 mg Q8H & $\begin{array}{l}1 \mathrm{~g} \mathrm{LD} \text { then } \\
750 \mathrm{mg} \text { Q8H }\end{array}$ \\
\hline & & $20-25$ & $\begin{array}{l}1 \mathrm{~g} \mathrm{LD} \text { then } \\
750 \mathrm{mg} \mathrm{Q8H}\end{array}$ & $1 \mathrm{~g} \mathrm{Q8H}$ \\
\hline & & 35 & $1 \mathrm{~g} \mathrm{Q8H}$ & $1 \mathrm{~g} \mathrm{Q8H}$ \\
\hline \multirow[t]{3}{*}{8} & 32 & $10-15$ & $\begin{array}{l}1.75 \mathrm{~g} \mathrm{LD} \text { then } \\
1.5 \mathrm{~g} \mathrm{Q} 8 \mathrm{H}\end{array}$ & $\begin{array}{l}1.75 \mathrm{~g} \mathrm{LD} \text { then } \\
1.5 \mathrm{~g} \mathrm{Q8H}\end{array}$ \\
\hline & & $20-25$ & $\begin{array}{l}2 \mathrm{~g} \mathrm{LD} \text { then } \\
1.5 \mathrm{~g} \mathrm{Q} 8 \mathrm{H}\end{array}$ & $1.75 \mathrm{~g} \mathrm{Q8H}$ \\
\hline & & 35 & $\begin{array}{l}2 \mathrm{~g} \mathrm{LD} \text { then } \\
1.75 \mathrm{~g} \mathrm{Q} 8 \mathrm{H}\end{array}$ & $2 \mathrm{~g} \mathrm{Q8H}$ \\
\hline
\end{tabular}

CVVH continuous venovenous hemofiltration, CVVHD continuous venovenous hemodialysis, $L D$ loading dose

*Pharmacodynamic target defined as at least $70 \%$ of the cumulative percentage of a 48 -h period with four times $\mathrm{MIC}(70 \% \mathrm{fT}>4 \mathrm{MIC})$

Some drugs can be removed by membrane interaction known as the adsorption phenomenon. Although the clinical significance has not been evaluated, CRRT hemofilter types do not significantly affect extracorporeal drug clearance and selection of drug dosing regimen due to early saturation of this phenomenon [20].
Owing to the assumption of MCS that generates only adult patients using pharmacokinetic parameters from previously published studies and ICU patient's body weights, those recommendations of cefepime should be applied for only patients who match our assumption such as anuric patients, same effluent flow rates. Another limitation of our study is the MIC breakpoint from

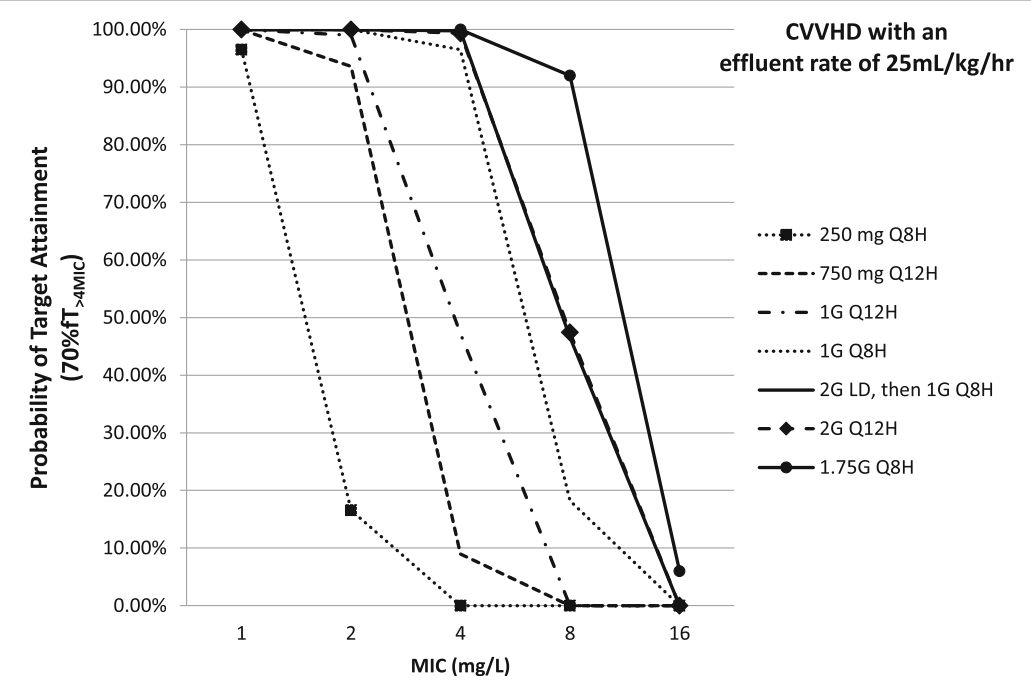

Fig. 1 PTA results of cefepime dosing regimens at different MICs in CWHD and $25 \mathrm{~mL} / \mathrm{kg} / \mathrm{h}$ effluent rate for management of Gram-negative infections caused by P. aeruginosa (> 70\% $\mathrm{fT}_{>4 \text { MIC; }}$ MIC of $8 \mathrm{mg} / \mathrm{L}$ ) in virtual patients for the first $48 \mathrm{~h}$ 
the Clinical Laboratory Standards Institute [31] used in the models. This value of $8 \mathrm{mg} / \mathrm{L}$ in the study implies a worst situation of when a susceptible $P$. aeruginosa for cefepime is reported. The dosing recommendations therefore would be adjusted for the settings that have lower reported MICs as shown in Table 5 and Fig. 1. In addition, $\mathrm{Su}$ and colleagues conducted a hospital-based retrospective study in 90 hospitalized patients. The results showed that the survival rate of patients with a positive blood culture for susceptible $P$. aeruginosa receiving cefepime as the primary therapy was significantly lower in a group with a higher MIC $(>4 \mathrm{mg} / \mathrm{L})$ compared with that in the lower MIC group $(<4 \mathrm{mg} / \mathrm{L})$ ( $72.6 \%$ vs $23.5 \%, p<0.0001)$ [35]. Consequently, we suggested to dose cefepime based on MIC values of each setting (Table 5). An alternative therapy might be considered when a patient who has $P$. aeruginosa infection with a cefepime MIC of $>4 \mathrm{mg} / \mathrm{L}$ was identified.

Clinical validation of these results is warranted. Reconsidering using these regimens from clinically available resources in critically ill patients would be suggested, and close monitoring of efficacy when prescribing the conventional dosing regimen is very important.

\section{Conclusion}

The MCS technique can be a valuable tool for evaluating drug dosing in critically ill patients receiving CRRT when limited pharmacokinetic data is a major concern. These results revealed that the optimal doses for critically ill patient receiving CRRT were higher than recommended doses form clinical available resources for treating $P$. aeruginosa. The dosing regimen of $2 \mathrm{~g} \mathrm{LD}$ was followed by $1500-1750 \mathrm{mg}$ every $8 \mathrm{~h}$ for critically ill patients receiving CRRT with KDIGO-recommended effluent rates. If the higher effluent rate is prescribed, drug doses should be increased. The MIC values of each setting were an important factor to design cefepime dosing regimens. Clinical study is absolutely needed to validate our recommendations.

\footnotetext{
Abbreviations

AKI: Acute kidney injury; CL: Clearance; $\mathrm{CL}_{H \mathrm{HD}}$ : Transmembrane clearance; $\mathrm{CL}_{\mathrm{HF}}$ : Transmembrane clearance; $\mathrm{CL}_{\mathrm{NR}}$ : Non-renal clearance; CLSI: Clinical Laboratory Standards Institute; CRRT: Continuous renal replacement therapy; $\mathrm{CWH}$ : Continuous venovenous hemofiltration; CWHD: Continuous venovenous hemodialysis; $\mathrm{fT}_{>4 \mathrm{MI}}$ : The cumulative percentage of a 48 -h period with four times MIC; g: Gram; h: Hour; ISN: International Society of Nephrology; k: Elimination rate constant; KDIGO: Kidney Disease: Improving Global Outcomes; kg: Kilogram; L: Liter; LD: Loading dose; MCS: Monte Carlo simulations; mg: Milligram; MIC: Minimum inhibitory concentration; mL: Milliliter; N: Number; PTA: Probability of target attainment; q: Every; $Q_{\text {blood: }}$ Blood flow rate; $Q_{d}$ : Dialysate flow rate; $Q_{\text {plasma: }}$ Plasma flow rate; $Q_{\text {replacement: }}$ Replacement fluid flow rate; $Q_{\text {uf: }}$ Ultrafiltrate flow rate; $r^{2}$ : Population-specific correlation; SA: Saturation coefficient; SC: Sieving coefficient; SD: Standard deviation; SEA-AKI: Southeast Asia entitled The Epidemiology and Prognostic Factors for Mortality in Intensive Care Unit Patients with Acute Kidney Injury in Southeast Asia; $V_{d}$ : Volume of distribution
}

\section{Acknowledgements}

We would like to thank Associate Professor Dr. Wibul Wongpoowarak for the helpful comments of our simulations in the study and Associate Professor Dr. Chalermsri Pummangura for all great advice and support. We also would like to thank Assistant Professor Dr. Dhakrit Rungkitwattanakul for proof reading the article.

\section{Funding}

This study was supported by a grant from the Siam University. The funding source had no role in the study design, the collection, analysis and interpretation of data, the writing of the article, and the decision to submit it for publication.

\section{Availability of data and materials}

The datasets used and/or analyzed during the current study are available from the corresponding author on reasonable request.

\section{Authors' contributions}

WC contributed to the conception and design, acquisition of data, analysis and interpretation of data, and drafting and revising the manuscript. TC and $A B$ analyzed and interpreted the data regarding simulations and probability of target attainment. NS was involved in data collection and drafting and revising the manuscript. SP interpreted the data regarding simulations and probability of target attainment and was also involved in drafting and revising the manuscript. All authors read and approved the final manuscript.

Ethics approval and consent to participate

Not applicable.

Consent for publication

Not applicable.

\section{Competing interests}

The authors declare that they have no competing interests.

\section{Publisher's Note}

Springer Nature remains neutral with regard to jurisdictional claims in published maps and institutional affiliations.

\section{Author details}

${ }^{1}$ Faculty of Pharmacy, Siam University, 38 Petkasem Road, Bangwa, Pasicharoen, Bangkok 10160, Thailand. 'Division of Nephrology, Department of Medicine, Faculty of Medicine, Chulalongkorn University, and King Chulalongkorn Memorial Hospital, Bangkok, Thailand. ${ }^{3}$ Department of Clinical Pharmacy, Faculty of Pharmaceutical Sciences, Prince of Songkla University, Songkhla, Thailand. ${ }^{4}$ School of Pharmaceutical Sciences, University of Phayao, Phayao, Thailand.

Received: 2 July 2018 Accepted: 30 August 2018

Published online: 12 September 2018

\section{References}

1. Kidney Disease: Improving global outcomes (KDIGO) acute kidney injury work group. KDIGO clinical practice guideline for acute kidney injury. Kidney Inter Suppl 2012; 2: 1-138.

2. Maxipime ${ }^{\oplus}$ [package insert]. Lake Forest, IL: Hospira, Inc; 2012.

3. Nye KJ, Shi YG, Andrews JM, Wise R. Pharmacokinetics and tissue penetration of cefepime. J Antimicrob Chemother. 1989;24:23-8.

4. Barbhaiya RH, Knupp CA, Forgue ST, Matzke GR, Guay DRP, Pittman KA. Pharmacokinetics of cefepime in subjects with renal insufficiency. Clin Pharmacol Ther. 1990;48:268-76.

5. Shaw AR, Chaijamorn W, Mueller BA. We underdose antibiotics in patients on CRRT. Semin Dial. 2016;29(4):278-80.

6. Kollef MF, Sherman G, Ward S, Fraser VJ, et al. Inadequate antimicrobial treatment of infections: a risk factor for hospital mortality among critically ill patients. Chest. 1999;115:462-74.

7. Lewis SJ, Mueller BA. Antibiotic dosing in patients with kidney injury; "enough but not too much". J Intensive Care Med. 2016;31:164-76.

8. Isla A, Gascon AR, Maynar J, Arzuaga A, Toral D, Pedraz JL. Cefepime and continuous renal replacement therapy (CRRT): in vitro permeability of two 
CRRT membranes and pharmacokinetics in four critically ill patients. Clin Ther. 2005;27(5):599-608.

9. Malone RS, Fish DN, Abraham E, Teitelbaum I. Pharmacokinetics of cefepime during continuous renal replacement therapy in critically ill patients. Antimicrob Agents Chemother. 2001;45(11):3148-55.

10. Li AM, Gomersall CD, Choi G, Tian Q, Joynt GM, Lipman J, et al. A systematic review of antibiotic dosing regimens for septic patients receiving continuous renal replacement therapy: do current studies supply sufficient data? J Antimicrob Chemother. 2009;64:929-37.

11. Barbey F, Bugnon D, Wauters JP. Severe neurotoxicity of cefepime in uremic patients (letter). Ann Intern Med. 2001;135:1011.

12. Chatellier D, Jourdain M, Mangalaboyi J, Ader F, Chopin C, Derambure P, et al. Cefepime-induced neurotoxicity: an underestimated complication of antibiotherapy in patients with acute renal failure. Intensive Care Med. 2002; 28:214-7.

13. Lam S, Gomolin IH. Cefepime neurotoxicity: case report, pharmacokinetic considerations, and literature review. Pharmacotherapy. 2006;26:1 169-74.

14. Durand-Maugard C, Lemaire-Hurtel AS, Gras-Champel V, Hary L, Maizel J, Prud'homme-Bernardy A, et al. Blood and CSF monitoring of cefepimeinduced neurotoxicity: nine case reports. J Antimicrob Chemother. 2012; 67(5):1297-9.

15. Wong KM, Chan WK, Chan YH, Li CS. Cefepime-related neurotoxicity in a haemodialysis patient. Nephrol Dial Transplant. 1999:14:2265-6.

16. Allaouchiche B, Breilh D, Jaumain H, Gaillard B, Renard S, Saux MC. Pharmacokinetics of cefepime during continuous venovenous hemodiafiltration. Antimicrob Agents Chemother. 1997;41(11):2424-7.

17. Beumier M, Casu GS, Hites M, Seyler L, Cotton F, Vincent JL, et al. Betalactam antibiotic concentrations during continuous renal replacement therapy. Crit Care. 2014;18(3):R105.

18. Seyler L, Cotton F, Taccone FS, De Backer D, Macours P, Vincent $J$, et al. Recommended beta-lactam regimens are inadequate in septic patients treated with continuous renal replacement therapy. Crit Care. 2011;15(3):R137

19. Carlier M, Taccone FS, Beumier M, Seyler L, Cotton F, Jacobs F, et al. Population pharmacokinetics and dosing simulations of cefepime in septic shock patients receving continuous renal replacement therapy. Int J Antimicrob Agents. 2015;46:413-9.

20. Schetz M. Drug dosing in continuous renal replacement therapy: general rules. Curr Opin Crit Care. 2007;13(6):645-51.

21. International Society of Nephrology (ISN). Clinical research: the epidemiology and prognostic factors for mortality in intensive care unit patients with acute kidney injury in South East Asia. Available from https:// www.theisn.org/component/k2/item/2645-clinical-research-theepidemiology-and-prognostic-factors-for-mortality-in-intensive-care-unitpatients-with-acute-kidney-injury-in-south-east-asia. Accessed 2 Feb 2018.

22. Legrand M, Darmon M, Joannidis M, Payen D. Management of renal replacement therapy in ICU patients: an international survey. Intensive Care Med. 2013;39:101-8.

23. Aronoff GR, Bennett WM, Berns JS, Brier ME, Kasbekar N, Mueller BA, et al. Drug prescribing in renal failure: dosing guidelines for adults and children. 5th ed. Philadephia: American College of Physicians; 2007.

24. Trotman RL, Williamson JC, Shoemaker DM, Salzer WL. Antibiotic dosing in critically ill adult patients receiving continuous renal replacement therapy. Clin Infect Dis. 2005;41(8):1159-66.

25. Heintz BH, Matzke GR, Dager WE. Antimicrobial dosing concepts and recommendations for critically ill adult patients receiving continuous renal replacement therapy or intermittent hemodialysis. Pharmacotherapy. 2009; 29(5):562-77.

26. Lewis SJ, Chaijamorn W, Shaw AR, Mueller BA. In silico trials using Monte Carlo simulation to evaluate ciprofloxacin and levofloxacin dosing in critically ill patients receiving prolonged intermittent renal replacement therapy. Ren Replace Ther. 2016;2:45.

27. Lewis SJ, Kays MB, Mueller BA. Use of Monte Carlo simulations to determine optimal Carbapenem dosing in critically ill patients receiving prolonged intermittent renal replacement therapy. J Clin Pharmacol. 2016;56(10):1277-87.

28. Mouton JW, Dudley MN, Cars O, Derendorf H, Drusano GL. Standardization of pharmacokinetic/pharmacodynamics (PK/PD) terminology for antiinfective drugs: an update. J Antimicrob Chemother. 2005;55:601-7.

29. Tam VH, McKinnon PS, Akins RL, Rybak MJ, Drusano GL. Pharmacodynamics of cefepime in patients with gram-negative infections. J Antimicrob Chemother. 2002;50:425-8,
30. Drusano GL. Antimicrobial pharmacodynamics: critical interactions of 'bug and grug'. Nat Rev Microbiol. 2004;2:289-300.

31. Clinical Laboratory Standards Institute. Performance Standards for Antimicrobial Susceptibility Testing, ed 26. CLSI supplement M100S. Wayne: CLSI; 2016.

32. Lewis SJ, Mueller BA. Antibiotic dosing in critically ill patients receiving CRRT: underdosing is overprevalent. Semin Dial. 2014;27(5):441-5.

33. Barbhaiya RH, Knupp CA, Tenney J, Martin RR, Weidler DJ, Pittman KA. Safety, tolerance, and pharmacokinetics of cefepime administered intramuscularly to healthy subjects. J Clin Pharmacol. 1990;30:900-10.

34. Finfer S, Bellomo R, McEvoy S, Lo SK, Myburgh J, Neal B, et al. Effect of baseline serum albumin concentration on outcome of resuscitation with albumin or saline in patients in intensive care units: analysis of data from the saline versus albumin fluid evaluation (SAFE) study. BMJ. 2006;333:1044.

35. Su TY, Ye JJ, Yang CC, Huang CT, Chia JH, Lee MH. Influence of borderline cefepime MIC on the outcome of cefepime-susceptible Pseudomonas aeruginosa bacteremia treated with a maximal cefepime dose: a hospitalbased retrospective study. Ann Clin Microbiol Antimicrob. 2017;16(1):52.

\section{Ready to submit your research? Choose BMC and benefit from:}

- fast, convenient online submission

- thorough peer review by experienced researchers in your field

- rapid publication on acceptance

- support for research data, including large and complex data types

- gold Open Access which fosters wider collaboration and increased citations

- maximum visibility for your research: over $100 \mathrm{M}$ website views per year

At BMC, research is always in progress.

Learn more biomedcentral.com/submissions 